\title{
Winter habitat selection by the Vulnerable black-necked crane Grus nigricollis in Yunnan, China: implications for determining effective conservation actions
}

\author{
Kong De-Jun, Yang XiaO-Jun, Liu Qiang, Zhong Xing-YAo and \\ YANG JUN-XING
}

\begin{abstract}
Habitat change has major effects on wildlife and it is important to understand how wild animals respond to changing habitats. Dashanbao National Nature Reserve, in north-east Yunnan, China, which was established for the protection of the black-necked crane Grus nigricollis, other wintering waterbirds and the upland wetland ecosystem, recently began converting farmland to grassland and woodland. With respect to this policy we studied habitat selection by black-necked cranes in the Reserve from November 2006 to April 2007. Farmland, grassland, marsh and water were used by black-necked cranes but no cranes occurred in man-made woodland. Black-necked cranes showed the least preference for grassland and no significant differences were detected in the species' preference for the other three habitats. However, black-necked cranes exhibited different behavioural responses to the four habitats: farmland and grassland were their main foraging sites. Principle component analysis verified that a foragingrelated component was the first factor determining habitat selection. Cranes used habitat close to their roosts with short grass, shallow water and less disturbance by human activity. Our results indicate that the policy of converting farmland and grassland to woodland is not beneficial for conservation of the crane. For effective conservation of the black-necked crane scientific habitat management that takes into account habitat selection by the species is required, with the retention of some farmland and restoration of wetlands.
\end{abstract}

Keywords Black-necked crane, China, conservation action, Dashanbao, Grus nigricollis, habitat selection, Yunnan

Kong De-Jun*, YANG XIAO-JUn (Corresponding author), LiU QIANG* and YANG Jun-XING State Key Laboratory of Genetic Resources and Evolution, Kunming Institute of Zoology, the Chinese Academy of Sciences, Kunming, Yunnan 650223, China. E-mail: yangxj@mail.kiz.ac.cn

Zhong XING-YAO Administrative Bureau, Dashanbao National Nature Reserve, Zhaotong, Yunnan, China

*Also at: Graduate University of the Chinese Academy of Sciences, Beijing, China

Received 28 June 2009. Revision requested 23 November 2009.

Accepted 9 March 2010.

\section{Introduction}

T abitat selection is a hierarchical process of behavioural 1 responses that may result in a disproportionate use of habitats for the survival and fitness of individuals (Johnson, 1980; Block \& Brennan, 1993). Studies of habitat selection have assumed a new urgency as a result of the importance of incorporating both habitat and demographic information into conservation planning (Caughley, 1994). An understanding of habitat selection and an explicit consideration of fitness consequences is a precondition for enhancing the survival of species (Tirpak et al., 2008) and needs to be carefully considered in conservation planning.

Black-necked cranes Grus nigricollis live their entire life on high plateaus, primarily in western China, with the eastern population breeding on the Qinghai-Tibet Plateau and wintering on the lower Yunnan-Guizhou Plateau. The global population is estimated to be c. 8,000 ( $\mathrm{Li} \& \mathrm{Li}, 2005)$ and the species is categorized as Vulnerable on the IUCN Red List (BirdLife International, 2009) and listed in Appendix I of CITES (Inskipp \& Gillett, 2005). Dashanbao National Nature Reserve in north-east Yunnan plays an important role in the conservation of the species (Kong, 2008), with the largest population wintering on the Yunnan-Guizhou Plateau, and the Reserve is one of the most important stopover sites for the eastern black-necked crane population (Li \& Yang, 2003; Qian et al., 2009). The species has been little studied because of the remoteness of its breeding and wintering areas (Meine \& Archibald, 1996). Loss and degradation of habitat as a result of increasing anthropogenic pressures are the principal threats to this species, especially in its winter range (Yang, 1991; Bishop, 2006).

Although there have been many studies of habitat selection by crane species (Díaz et al., 1996; Ma et al., 1999; Végvári, 2002; Avilés, 2004) this is not the case for the blacknecked crane. Of the few studies, Zhou et al. (1987) observed black-necked cranes selecting marshland as their main winter habitat in Caohai Reserve, Guizhou, China, and there have been descriptive analyses of the vegetation of the species' habitat in north-east Yunnan (Li et al., 2005) and of a feeding site in Dashanbao National Nature Reserve (Liu et al., 2006). A study at Caohai quantified selection of winter foraging 
habitat by black-necked cranes, finding that sedge meadow was preferentially selected, followed by grassland and farmland (Li, 1999). These studies, however, did not include data on crane behaviour. Habitat selection is a decision-making process (Jason, 2001) and it is important to study behaviour in habitat selection research.

Landscape changes that increase or decrease certain habitats may have significant effects on species and any such changes need to be considered by reserve managers. To improve environmental quality in central and western China the government implemented a policy in 1999 of conversion of farmland to grassland and woodland, with compensation to local farmers (Chinese State Council, 2007). Dashanbao National Nature Reserve recently implemented this policy. Based on conclusions presented in $\mathrm{Li}$ (1999) we hypothesized that such land-use conversion would increase the preferred habitat available for blacknecked cranes and attract more individuals to the Reserve. If the hypothesis is correct this action would be an effective conservation measure and should thus be encouraged.

In this study we focused on four aspects of habitat selection by black-necked cranes: (1) How do they use their wintering habitat? (2) What kind of habitat do they prefer (habitat preference is the consequence of habitat selection; Krausman, 1999)? (3) Which environmental factors drive habitat selection in winter? (4) What are the characteristics of habitats selected by the species?

\section{Study area}

We conducted this study between November 2006 and April 2007 in the 19,200 ha Dashanbao National Nature Reserve in north-east Yunnan Province, China. The Reserve was established in 1994 for the protection of the black-necked crane, other wintering waterbirds and the upland wetland ecosystem (Zhong \& Dao, 2005). In 2005 the Reserve was included in the Ramsar List of Wetlands of International Importance (Ramsar Convention Secretariat, 2008). The landscape of the Reserve, which lies at altitudes of 3,000-3,200 $\mathrm{m}$, comprises rolling hills, plains and valleys, with rivers, streams and lakes, and patches of farmland and meadows in the valleys and on the hills. A total of c. 1,200 black-necked cranes winter in the Reserve each year, roosting at four lake-side sites (Kong, 2008). To avoid the cranes starving during periods of heavy snow, Reserve staff provision them with corn Zea mays on the marsh near to the biggest roost at Dahaizi Lake. However, only c. $3 \mathrm{~kg}$ of corn has ever been supplied on any one day and no more than 50 cranes were ever attracted to eat it (KD-J, unpubl. data), indicating that artificial feeding had little impact on habitat use and selection by the cranes. Our study area covered 1,659 ha (Fig. 1) and encompassed the biggest roost, at Dahaizi Lake.

\section{Methods}

Wintering cranes are gregarious and fly each morning from a communal roost to feed in surrounding areas, returning at night (Cramp \& Simmons, 1985). We spent 2 days every week for 22 weeks observing the cranes whilst they fed. We selected two transect routes in the study area in October 2006, before our study started, without prior knowledge of areas favoured by the species. All black-necked cranes in the study area could be detected from the $9.5 \mathrm{~km}$ of transects, which were along a mountain ridge (Fig. 1). The positions of all flocks were located on 1:50,000 maps to facilitate calculation of distances. We walked transects once per day and switched direction of travel on subsequent days. We defined flocks as being discrete if they were more than $200 \mathrm{~m}$ apart (Li \& Ma, 1992), and every flock was considered an independent sample.

For each flock we used instantaneous scan sampling with 3-minute intervals to collect behavioural data. Five scans were made of every flock on every study day (Altmann, 1974). We observed another flock once the five scans were completed, and ceased scanning when cranes flew away. We categorized crane behaviours into foraging, vigilance, walking and preening. Foraging included all behaviours related to feeding, such as searching, dealing with food and swallowing. Vigilance included gazing or observing with neck stretched, ritualistic threatening and fighting. Walking included all movements except for food searching, flying and walking while in vigilance. All activities related to self-maintenance were defined as preening.

We calculated the area of the study site by analysing remotely sensed images (Landsat ETM+. path/row 129/041, resolution $15 \times 15 \mathrm{~m}$; June 2001). We ground-truthed habitat composition using 105 point observations $50 \mathrm{~m}$ apart along the transects. Five habitat categories were distinguished: farmland, grassland, marsh, water and man-made woodland (Fig. 1). Farmland included ploughed and unploughed cereal and potato fields and Rorippa indica fields. Grassland comprised meadows with minimal water. Marsh comprised both wetlands around the lake and meadows with large areas of water. Cranes usually used areas with water no deeper than $100 \mathrm{~cm}$. Man-made woodland comprised areas planted with Chinese white pine Pinus armandii and Sikang pine Pinus densata.

We recorded the following details for each flock: habitat category, location, flock size, slope, slope direction (if there was slope, we regarded 1 as north and 3, 5 and 7 as east, south and west, respectively), distance to roost, distance to the nearest water, water depth and grass height. On 2 days per month we counted the number of people passing by in 30 minutes at each location where cranes occurred and this variable was regarded as disturbance.

To calculate time budgets we determined the time allocated to each activity as the percentage of scanned 


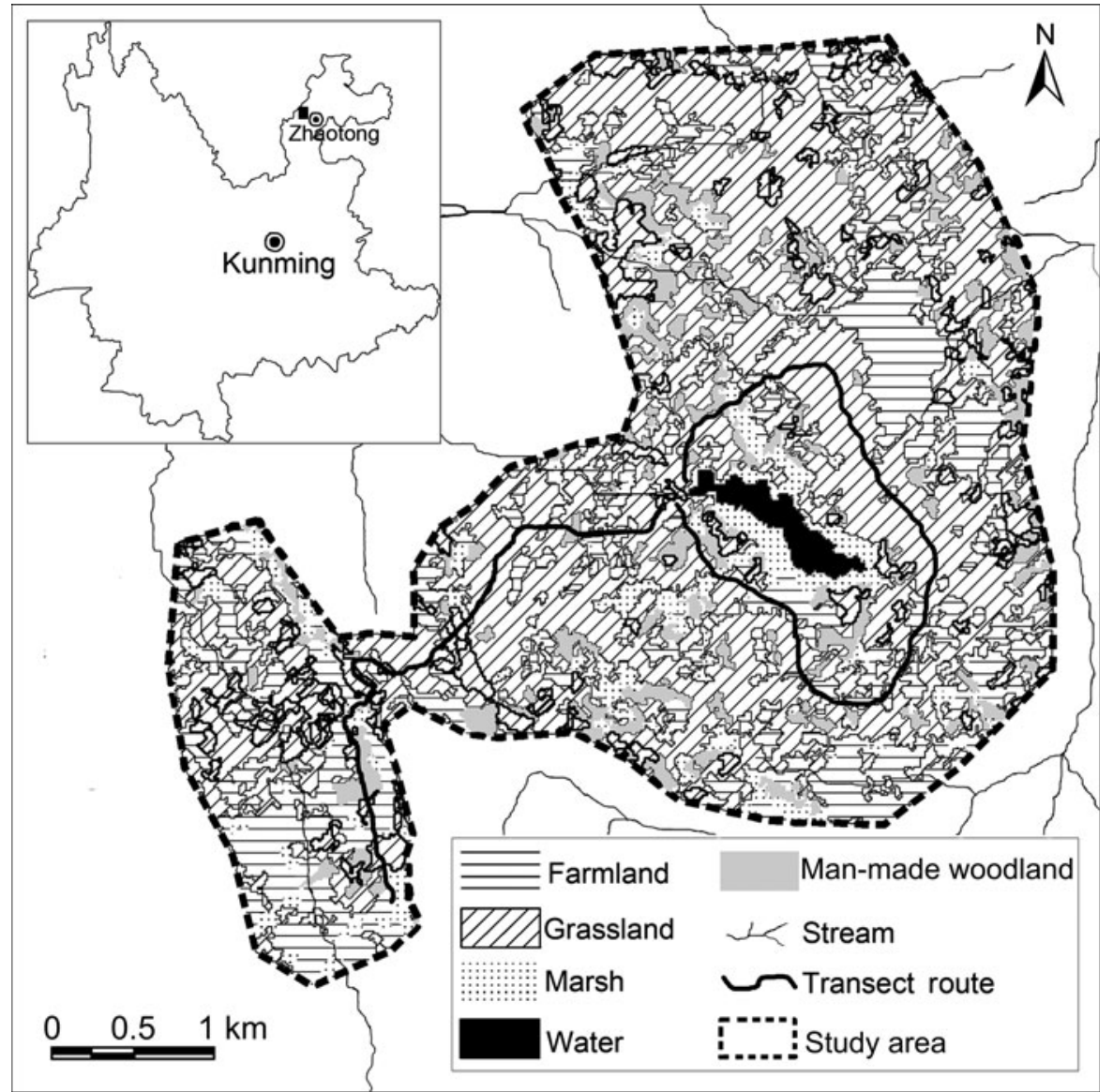

FIG. 1 Habitat distribution interpreted from a Landsat ETM+ image of the study area and transect routes in Dashanbao National Nature Reserve. The rectangle on the inset indicates the location of the main figure in north-east Yunnan, China.

individuals engaging in each activity. The mean of the five scans was treated as an independent data point and used in subsequent analysis; this can reduce potential biases introduced by scan sampling (Clutton-Brock, 1977). For each array of data the Kolmogorov-Smirnov test was used to check normality. Subsequently we used parametric and non-parametric tests as appropriate (Zar, 1999). To avoid the unit-sum constraint of habitat categories (the sum of the habitat categories equals one), habitat preference (which takes into account habitat availability) was determined using the method of compositional analysis, evaluating the relative magnitude of the log-transformed ratio of every two habitat categories instead of the absolute value (Bingham \& Brennan, 2004). The calculation is $d_{i j}=$ $\ln \left(\chi_{U i} / \chi_{U j}\right)-\ln \left(\chi_{A i} / \chi_{A j}\right)$, where $i$ and $j$ represent the $i$ th and $j$ th habitat category and $i \neq j ; \chi_{U}$ and $\chi_{A}$ are habitat proportion utilized and available, respectively. When $d_{i j}>0$ habitat $i$ is used more than expected relative to habitat $j$, otherwise habitat $i$ is used less than expected. The equation was used to construct a ranking matrix (Aebischer et al., 1993). A two independent samples test was used to evaluate any differences between log-transformed observed habitat preference and availability of habitat. A one-way analysis of variance was used to test for differences in the seasonality of habitat use. For post hoc multiple comparisons of time budget between different habitat categories we used Tamhane's $\mathrm{T}_{2}$ method because the data violated the homogeneity of variance assumption (Myers \& Well, 2003).

As both biotic and abiotic factors could influence habitat selection and there could be interactions amongst these factors (Krausman, 1999) we used principal components analysis (PCA) to determine the key factors that affect habitat use (McGarigal et al., 2000). The variables used in the PCA were distance to roost $(\leq 1,000,>1,000$ and $\leq 2,000$, $>2,000 \mathrm{~m})$, distance to the nearest water $(\leq 1,000$, $>1,000 \mathrm{~m}$ ), slope $\left(\leq 10,>10^{\circ}\right)$, slope direction (north to east, east to south, south to west, west to north), water depth ( $\leq 5,>5$ $\mathrm{cm})$, grass height $(\leq 10,>10 \mathrm{~cm})$ and number of pedestrians $(\leq 5,>5$ individuals per 30 minutes). We extracted those principal components with an eigenvalue $>1$. We used SPSS $v$. 13.o (SPSS Inc., Chicago, USA) for statistical analysis and considered two-tailed probabilities of 0.05 for significance.

\section{Results}

We observed 505 independent crane flocks; 55, 23, 14 and $8 \%$ of these were observed on farmland, grassland, marsh and water areas, respectively (Table 1 ). We did not see any 
TABLE 1 The area of each of the four habitats in which blacknecked cranes Grus nigricollis were observed in Dashanbao National Nature Reserve (Fig. 1), with the percentage availability of each habitat, number of crane flocks observed, and percentage use by cranes of each habitat (based on observations). Man-made woodland is not included as cranes were not observed there. Although the total study area covered 1,659 ha, 154.6 ha of this is woodland and villages, and thus the total area of the four habitats is 1504.4 ha.

\begin{tabular}{|c|c|c|c|c|c|}
\hline & \multicolumn{4}{|c|}{ Habitat type } & \multirow[b]{2}{*}{ Total } \\
\hline & Farmland & Grassland & Marsh & Water & \\
\hline Area (ha) & 413.2 & 932.5 & 138.8 & 19.9 & $1,504.4$ \\
\hline $\begin{array}{l}\text { Habitat } \\
\quad \text { availability (\%) }\end{array}$ & 27.5 & 62.0 & 9.2 & 1.3 & 100 \\
\hline $\begin{array}{c}\text { No. of flocks } \\
\text { observed }\end{array}$ & 278 & 115 & 72 & 40 & 505 \\
\hline Habitat use (\%) & 55.1 & 22.8 & 14.2 & 7.9 & 100 \\
\hline
\end{tabular}

cranes in man-made woodland. There was no difference in habitat utilization between months (least significant difference $\mathrm{P}>0.05$; Fig. 2). The cranes utilized the four habitats randomly $\left(t_{4}=0.250, \mathrm{P}=0.815\right)$. The ranking of habitat preference based on compositional analysis was water $>$ farmland $>$ marsh $>$ grassland (Table 2). There was no detectable difference in preference for the three top-ranked habitat categories (least significant difference $\mathrm{P}>0.05$ ) but grassland was preferred significantly less than water and farmland (largest significant difference $\mathrm{P}<0.05$ ).

Time spent foraging was mostly in farmland and grassland (Fig. 3) and there was no significant difference
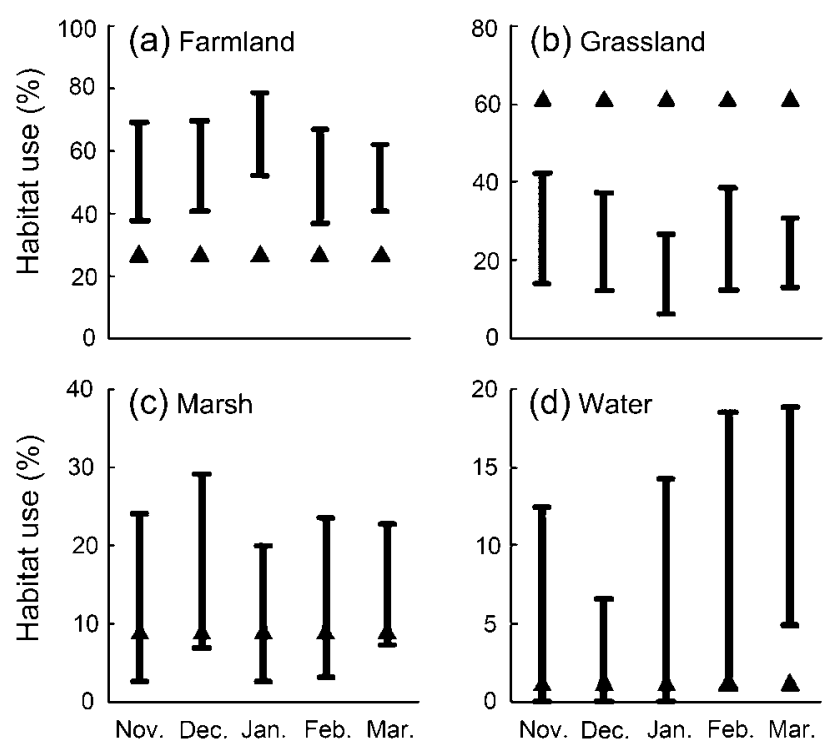

FIg. 2 Percentage use of (a) farmland, (b) grassland, (c) marsh and (d) water by black-necked cranes Grus nigricollis in the winter of 2006-2007 (November-March) in Dashanbao National Nature Reserve (Fig. 1). The black bars represent habitat use based on observations of flocks and the triangles represent expected use based on availability. Note the different $y$-axis dimensions.
TABLE 2 The results of the evaluation of habitat preference by black-necked cranes G. nigricollis in Dashanbao National Nature Reserve (Fig. 1) using compositional analysis (see text for details). This ranking matrix was constructed with the log-transformed ratio of every two habitat category components, based on utilization and availability of habitats. Rank was determined by the number of positive values in each row (Aebischer et al., 1993).

\begin{tabular}{lllrll}
\hline $\begin{array}{l}\text { Habitat types } \\
\text { (numerator) }\end{array}$ & \multicolumn{2}{l}{ Habitat type (denominator) } & \\
\cline { 2 - 5 } & Farmland & Grassland & Marsh & Water & Rank \\
\hline Farmland & & 1.697 & 0.260 & -1.092 & 2 \\
Grassland & -1.697 & & -1.437 & -2.789 & 0 \\
Marsh & -0.260 & 1.437 & & -1.352 & 1 \\
Water & 1.092 & 2.789 & 1.352 & & 3 \\
\hline
\end{tabular}

in time spent foraging between these two habitats (Tamhane's $\mathrm{T} 2$ : $\mathrm{P}=0.469$ ). There was, however, a significant difference between these two habitats and marsh and water (Tamhane's T2: $\mathrm{P}<0.001)$. Cranes spent significantly longer preening in water than in any other habitat (Tamhane's T2: $\mathrm{P}<0.001$ ) and more time preening in marsh than in farmland and grassland (Tamhane's T2: $\mathrm{P}<0.001)$. Cranes had higher vigilance in farmland compared to water (Tamhane's T2: $\mathrm{P}=0.026$ ) and walking did not differ significantly among the four habitats (Tamhane's T2: $\mathrm{P}>0.05$ ).

The first three components of the PCA explained a total of $74.5 \%$ of cumulative variance (Table 3$)$. PC1 (31\% of variance) was strongly affected by distance to roost, grass height and water depth, and is thus related to foraging. PC2

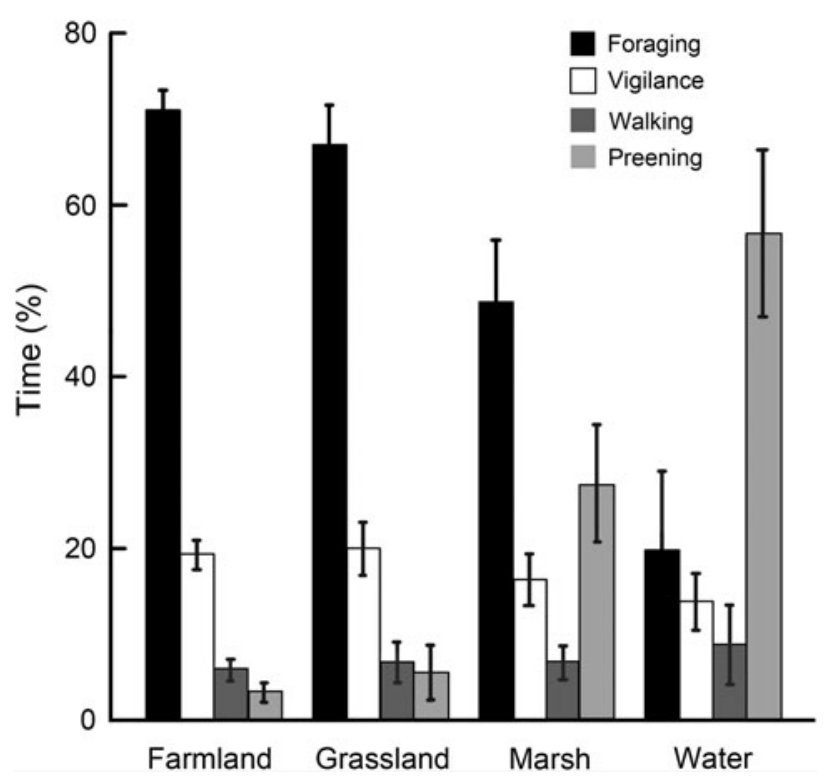

FIG. 3 Percentage of time (with 95\% confidence intervals) that black-necked cranes spent in foraging, vigilance, walking or preening in farmland, grassland, marsh and water in the winter of 2006-2007 in Dashanbao Nature Reserve (Fig. 1). 
TABLE 3 Results of principal components analysis (components 1-3) of seven variables potentially influencing habitat selection by wintering black-necked cranes G. nigricollis in Dashanbao National Nature Reserve (Fig. 1).

\begin{tabular}{lrrr}
\hline & \multicolumn{3}{l}{ Components } \\
\cline { 2 - 4 } Variable & \multicolumn{1}{l}{ r } & \multicolumn{1}{l}{3} \\
\hline Distance to roost & 0.797 & -0.060 & -0.023 \\
Grass height & -0.747 & 0.359 & 0.201 \\
Water depth & -0.741 & 0.365 & 0.206 \\
Distance to the & 0.585 & 0.302 & 0.522 \\
$\quad$ nearest water source & & & \\
Slope direction & 0.074 & 0.910 & -0.048 \\
Slope degree & 0.190 & 0.847 & 0.066 \\
No. of pedestrians & 0.209 & 0.060 & -0.880 \\
$\quad$ passing in 30 minutes & & & \\
Eigenvalue & 2.169 & 1.906 & 1.137 \\
\% of variance & 30.985 & 27.234 & 16.249 \\
\% of cumulative variance & 30.985 & 58.219 & 74.468 \\
\hline
\end{tabular}

(27.2\% of variance) was strongly influenced by slope direction and degree, and could be regarded as an energy-saving related component. $\mathrm{PC}_{3}$ ( $16.2 \%$ of variance) was most affected by the number of passing pedestrians. In general, our result showed that $>70 \%$ of cranes used habitat close to the roost $(\leq 2,000 \mathrm{~m})$, with short grass $(\leq 10 \mathrm{~cm})$, shallow water $(\leq 5 \mathrm{~cm})$, little disturbance $(\leq 5$ pedestrians passing per 30 minutes) and on slopes of $<10^{\circ}$ oriented north to east (Table 4).

\section{Discussion}

Because habitat selection refers to a series of behavioural processes (Johnson, 1980; Block \& Brennan, 1993) it is essential to combine time budgets together with habitat use in habitat selection analysis but this has not been done in previous studies of the black-necked crane (Li, 1999; Liu et al., 2006). Compared to simply defining which kind of habitat is used most frequently by a species, our method of including behavioural data in analysis of habitat selection could help biologists and conservationists understand more fully the role of different habitats in life histories.

Black-necked cranes avoided man-made woodland, probably because of space limitations for flight as this bird prefers large open areas (Johnsgard, 1983). The cranes also generally avoided grassland, preferring farmland, marsh and water; this is probably because of different levels of food availability in the four habitats, and possibly because of other physiological requirements. In Dashanbao $\mathrm{Na}$ tional Nature Reserve Avena sativa, Fagopyrum tataricum, Solanum tuberosum and $R$. indica are the dominant crops (Zhong \& Dao, 2005), and residues are left in farmlands after harvest, providing food for the cranes. Similarly, in Tibet farmland provides a large amount of food for blacknecked cranes (Bishop \& Li, 2002). A higher quantity and density of food and looser soil structure in farmland compared to grassland enhances food collection (KD-J, unpubl. data). Black-necked cranes used grassland the least in the middle of winter (especially January; Fig. 2), partly because of the frozen surface, which makes it difficult for them to find food (KD-J, pers. obs.).

We speculate that the cranes use farmland and grassland to obtain different types of food. Cereals, roots and tubers, such as A. sativa, F. tataricum, S. tuberosum and $R$. indica, can be found in farmland, whereas naturally occurring plants such as Pedicularis, Stellaria, Polygonatum and Veronica, and scarabid beetles, can be found in grassland (Li \& Zhong, 2010). Common cranes Grus grus in the Quercus ilex forests of Spain show a similar pattern of use

TABLE 4 The number and cumulative frequency of the 505 independent flocks of wintering black-necked cranes observed in our defined categories of seven habitat variables in Dashanbao National Nature Reserve (Fig. 1).

\begin{tabular}{|c|c|c|c|}
\hline Variable & & Flocks observed & $\%$ of cumulative frequency \\
\hline \multirow[t]{3}{*}{ Distance to roost $(\mathrm{m})$} & $\leq 1,000$ & 223 & 44.16 \\
\hline & $>1,000$ and $\leq 2,000$ & 145 & 72.87 \\
\hline & $>2,000$ & 137 & 100.00 \\
\hline \multirow[t]{2}{*}{ Grass height $(\mathrm{cm})$} & $\leq 10$ & 418 & 82.77 \\
\hline & $>10$ & 87 & 100.00 \\
\hline \multirow[t]{2}{*}{ Water depth $(\mathrm{cm})$} & $\leq 5$ & 415 & 82.18 \\
\hline & $>5$ & 90 & 100.00 \\
\hline \multirow[t]{2}{*}{ Distance to the nearest water source $(\mathrm{m})$} & $\leq 1,000$ & 444 & 87.92 \\
\hline & $>1,000$ & 61 & 100.00 \\
\hline \multirow[t]{4}{*}{ Slope direction } & North to east & 333 & 65.94 \\
\hline & East to south & 74 & 80.59 \\
\hline & South to west & 54 & 91.29 \\
\hline & West to north & 44 & 100.00 \\
\hline \multirow[t]{2}{*}{ Slope $\left(^{\circ}\right)$} & $\leq 10$ & 435 & 86.14 \\
\hline & $>10$ & 70 & 100.00 \\
\hline \multirow[t]{2}{*}{ No. of pedestrians passing in 30 minutes } & $\leq 5$ & 416 & 82.38 \\
\hline & $>5$ & 89 & 100.00 \\
\hline
\end{tabular}


of grasslands and farmlands for foraging (Díaz et al., 1996). Water, farmlands and marsh habitats provide various, but different, resources for cranes. We found that shallow water areas were used for roosting, social behaviours and as a water source (Kong et al., 2008). The marsh area is important for foraging and preening activities and is also a buffer that separates the cranes from disturbance ( $\mathrm{Wu}$ et al., 2010). A high preference of black-necked cranes for water areas, although these make up the smallest proportion of the Reserve, indicates the importance of this habitat, something also documented in a study of the blacknecked crane in Napahai, Yunnan (Liu et al., 2010).

The PCA confirmed that a foraging related component is the main factor determining habitat selection by the blacknecked crane. In Dashanbao National Nature Reserve blacknecked cranes avoid places far from their roost most likely to reduce fitness and increase energy losses (Belichon et al., 1996; Stamps et al., 2005), as do common cranes wintering in north-east Spain (Alonso \& Alonso, 1992). In habitats with short grass and shallow water the cranes may more easily be able to find food. The use of places with a shallow slope oriented north to east is probably an avoidance of the prevalent south-western winter wind, as found in a previous study in the Reserve (Liu et al., 2006).

Our results suggest that black-necked cranes do not benefit from the habitat conversion taking place in Dashanbao National Nature Reserve. Conversion of farmland to woodland should be halted because the cranes never use the man-made woodland. The conversion of farmland to grassland is also not favourable to the cranes because they prefer the former. Some farmland and crop residues are necessary for the survival of black-necked cranes in the Reserve in winter. We also recommend that the Reserve protects the small area of remaining wetlands and restores more wetlands.

\section{Acknowledgements}

This study was supported by the National Key Development Program for Fundamental Research (\#2007CB411600), the Western Light Associated Scholar Program of the Chinese Academy of Sciences and the International Crane Foundation Fund. We thank Dr Fan Peng-Fei for his guidance with experimental design and writing, Dr Li Feng-Shan, Dr Wu He-qi, Dr P. Buzzard and E. Doucet-Bëer for comments and suggestions, and the staff of Dashanbao National Nature Reserve for their valuable support in the field.

\section{References}

Aebischer, N.J., Robertson, P.A. \& Kenward, R.E. (1993) Compositional analysis of habitat use from animal radio-tracking data. Ecology, 74, 1313-1325.

Alonso, J.C. \& Alonso, J.A. (1992) Daily activity and intake rate patterns of wintering common cranes (Grus grus). Ardea, 80, 343-351.
Altmann, J. (1974) Observational study of behavior: sampling methods. Behavior, 49, 227-267.

Avilés, J.M. (2004) Common cranes (Grus grus) and habitat management in holm oak dehesas of Spain. Biodiversity and Conservation, 13, 2015-2025.

Belichon, S., Clobert, J. \& Massot, M. (1996) Are there differences in fitness components between philopatric and dispersing individuals? Acta Oecologia, 17, 503-217.

Bingham, R. \& BREnNAn, L.A. (2004) Comparison of type I error rates for statistical analyses of resource selection. Journal of Wildlife Management, 68, 206-212.

BirdLife International (2009) Grus nigricollis. In IUCN Red List of Threatened Species v. 2010.2. Http://www.iucnredlist.org [accessed 23 July 2010].

Bisнор, M.A. (2006) Black-necked crane (Grus nigricollis). Http:// www.npwrc.usgs.gov/resource/birds/cranes/grusnigr.htm. [accessed 17 June 2009].

Bisнop, M.A. \& Li, F.S. (2002) Effects of farming practices in Tibet on wintering black-necked cranes (Grus nigricollis) diet and food availability. Biodiversity Science, 10, 393-398.

BLOCK, W.M. \& BRENNAN, L.A. (1993) The habitat concept in ornithology: theory and applications. Current Ornithology, 11, $35-91$.

Caughley, G. (1994) Direction in conservation biology. Journal of Animal Ecology, 63, 215-244.

Chinese State Council (2007) Note on consummating the policies of converting farmland to forest. Http://www.gov.cn/zwgk/2007-08/ 14/content_716617.htm [accessed 14 August 2007]. [In Chinese]

Clutton-Brock, T.H. (1977) Appendix 1: methodology and measurement. In Primate Ecology: Studies of Feeding and Ranging Behavior in Lemurs, Monkeys, and Apes (ed. T.H. Clutton-Brock), pp. 585-590. Academic Press, London, UK.

Cramp, S. \& Simmons, K.E.L. (1985) The Birds of the Western Paleartic IV. Oxford University Press, Oxford, UK.

Díaz, M., González, E., Muñoz-Pulido, R. \& Naveso, M.A. (1996) Habitat selection patterns of common cranes (Grus grus) wintering in holm oak (Quercus ilex) dehesas of central Spain: effects of human management. Biological Conservation, 75, 119-123.

Inskipp, T. \& Gillett, H.J. (2005) Checklist of CITES Species and Annotated CITES Appendices and Reservations. Compiled by UNEP-WCMC. CITES Secretariat, Geneva, Switzerland, and UNEP-WCMC, Cambridge, UK.

JASON, J. (2001) Habitat selection studies in avian ecology: a critical review. The Auk, 118, 557-562.

Johnson, D.H. (1980) The comparison of usage and availability measurements for evaluating resource preference. Ecology, 61, 65-71.

JoHSG ARD, P.A. (1983) Cranes of the World. Indiana University Press, Bloomington, USA.

KonG, D.J. (2008) Studies on wintering behavior and conservation of Black-necked Cranes (Grus nigricollis) at Dashanbao, Yunnan, China. MSc thesis, Kunming Institute of Zoology, Chinese Academy of Sciences, Kunming, People's Republic of China.

KonG, D.J., YAnG, X.J., Zhong, X.Y., DAO, M.B. \& ZhU, Y. (2008) Diurnal time budget and behavior rhythm of wintering blacknecked crane at Dashanbao in Yunnan. Zoological Research, 29, 195-202.

Krausman, P.R. (1999) Some basic principles of habitat use. In Grazing Behaviour of Livestock and Wildlife (eds K.L. Launchbaugh, K.D. Sanders \& J.C. Mosley), pp. 85-90. University of Idaho, Moscow, USA.

LI, F.S. (1999) Foraging habitat selection of the wintering black-necked cranes in Caohai, Guizhou, China. Chinese Biodiversity, 7, 257-262.

LI, F.S., FAnG, S.Z. \& Guan, L.H. (2005) Preliminary survey on wintering environment of black-necked cranes in north-east 
Yunnan. In Status and Conservation of Black-Necked Cranes on the Yunnan and Guizhou Plateau. (eds F.S Li, X.J. Yang \& F. Yang), pp. 76-92. Yannan Nationalities Publishing House, Kunming, People's Republic of China.

LI, F.S. \& MA, J.Z. (1992) Wintering time budget and benefit study between family and group black-necked cranes. Chinese Wildlife, $3,36-41$.

LI, F.S. \& YANG, F. (2003) Population numbers and distribution of black-necked crane (Grus nigricollis) in the Yungui Gaoyuan Plateau. Chinese Journal of Zoology, 38, 43-46.

Li, H. \& Zhong, X.Y. (2010) Botany of Dashanbao National Nature Reserve, China. Scientific Press, Beijing, People's Republic of China.

Li, Z.M. \& LI, F.S. (2005) Black-Necked Crane Study. Shanghai Technological and Educational Press, Shanghai, People's Republic of China.

LiU, N., KuAnG, F.L., Xia, F. \& Zhong, X.Y. (2006) A primary study on feeding habitat use of black-necked cranes during winter. Journal of West Forestry Science, 35, 25-32.

LiU, Q., YANG, X.J., YanG, J.X., Zhao, J.L. \& Yu, H.Z. (2010) Foraging habitats and utilization distributions of Black-necked Cranes wintering at the Napahai wetland, China. Journal of Field Ornithology, 81, 21-30.

MA, Z.J., WANG, Z.J. \& TANG, H.X. (1999) Habitat use and selection by red-crowned crane (Grus japonensis) in winter in Yancheng Biosphere Reserve, China. Ibis, 141, 135-139.

McGarigal, K., Cushman, S. \& Stafford, S. (2000) Multivariate Statistics for Wildlife and Ecology Research. Springer Verlag, New York, USA.

Meine, C.D. \& Archibald, G.W. (1996) The Cranes: Status Survey and Conservation Action Plan. IUCN, Gland, Switzerland, and Cambridge, UK.

Myers, J.L. \& Well, A.D. (2003) Research Design and Statistical Analysis. Lawrence Erlbaum, Hillsdale, USA.

Qian, F.W., Wu, H.Q., GAO, L.B., ZhanG, H.G., Li, F.S., ZhONG, X.Y. et al. (2009) Migration routes and stopover sites for blacknecked cranes determined by satellite tracking. Journal of Field Ornithology, 80, 19-26.

Ramsar Convention Secretariat (2008) The Ramsar List of Wetlands of International Importance. Http://www.ramsar.org/pdf/sitelist.pdf. [accessed 4 August 2008].
Stamps, J.A., Krishnan, V.V. \& Reid, M.L. (2005) Search costs and habitat selection by dispersers. Ecology, 86, 510-518.

Tirpak, J.M., Giuliano, W.M. \& Miller, A. (2008) Ruffed grouse brood habitat selection at multiple scales in Pennsylvania: implications for survival. Canadian Journal of Zoology, 86, 329337.

VÉGVÁRI, Z. (2002) Autumn staging and habitat selection by common cranes (Grus grus) in the Hortobágy National Park, Hungary. Folia Zoology, 51, 221-225.

W A, H.Q., Zha, K., ZhanG, M. \& YAnG, X.J. (2009) Nest site selection by black-necked crane (Grus nigricollis) in the Ruoergai wetland, China. Bird Conservation International, 9, 277-286.

YANG, L. (1991) The distribution and habitats of the cranes in Yunnan province. In Proceedings 1987 International Crane Workshop (ed. J. Harris), pp. 127-130. International Crane Foundation, Baraboo, USA.

ZAR, J.H. (1999) Biostatistical Analysis. 4th ed. Prentice Hall, New Jersey, USA.

Zhong, X.Y. \& DAO, M.B. (2005) Cranes of the world. In Status and Conservation of Black-Necked Cranes on the Yunnan and Guizhou Plateau (eds F.S. Li, X.J. Yang \& F. Yang), pp. 101-106. Yannan Nationalities Publishing House, Kunming, People's Republic of China.

Zhou, F.Z., Ding, W.N. \& WANG, Z.Y. (1987) Observation on the wintering habitat of the black-necked crane. In Proceedings 1983 International Crane Workshop (eds G.W. Archibald \& R.F. Pasquier), pp. 41-44. International Crane Foundation, Baraboo, USA.

\section{Biographical sketches}

Kong De-Jun studies the behavioural ecology and conservation biology of the black-necked crane in China. YANG XIAO-JUN has interests in ornithological research and bird conservation. LIU QIANG works on wintering and migration ecology of the black-necked crane in China. ZHong XING-YAO is committed to the conservation and public awareness of the black-necked crane in Dashanbao reserve and more widely in China. YANG JUN-XING has broad interests, including animal taxonomy, evolution and biogeography of vertebrates in south-western China. 